\title{
EDITORIAL
}

\section{The Revolutionary Future of Bioelectronic Medicine}

\author{
Kevin J Tracey \\ The Feinstein Institute for Medical Research, Manhasset, New York, United States of America
}

Online address: www.bioelecmed.org

doi: 10.15424/bioelectronmed.2014.00001

A revolution can neither be made nor stopped.

\section{-Napoleon Bonaparte, 1769-1821}

Revolutions have played major roles over the course of history in cultural, political, economical and scientific disciplines. During my lifetime, I've had the opportunity to both witness and participate in a few revolutions. I was young when Sputnik launched, but I remember practicing duck-and-cover drills in school to avoid nuclear bombs. That revolution was quickly followed by President John F. Kennedy's promise to take a man safely to the moon and back before the decade was out. This galvanizing event in the United States launched the technology and scientific investment that we currently enjoy. It led directly to major investments in molecular biology, molecular medicine and technology. The effects of these revolutions have been long-lasting and have had a great impact.

We now have the opportunity to witness and participate in a new revolution. The rapid pace at which technology has evolved over the past several decades has changed the way we live and work. Now it will change the way we practice medicine. The intersection of technology, molecular medicine and molecular biology will allow us to develop devices and technologies to catalyze advances in the mechanistic understanding of disease. Individuals positioned to lead this effort where molecular biology meets technology will be creating a revolutionary new future, bioelectronic medicine.

Twenty years ago, we launched the international, peer-reviewed journal, Molecular Medicine. It was designed as a forum through which clinicians and researchers could communicate discoveries to a multidisciplinary audience in the then new, integrated field of molecular medicine. At the time, the field hoped to integrate concepts, tools and a common language and understanding to clinical groups as diverse as virologists and oncologists, dermatologists and neurologists (1). Today, we as a scientific community are heavily invested in molecular medicine and molecular biology. These investments have changed our understanding of science, changed the way medicine is practiced and changed our view of the world.

Once again, we find ourselves at the vanguard of a new field, bioelectronic

Address correspondence to Kevin J Tracey, The Feinstein Institute for Medical Research, 350 Community Drive, Manhasset, NY 11030. Phone: (516) 562-3467; Fax: (516) 562-2356; E-mail: kjtracey@nshs.edu.

Submitted June 19, 2014; Accepted for publication June 19, 2014; Published Online (www.bioelecmed.org) June 25, 2014.

\section{The Feinstein Institute for Medical Research Empowering Imagination. Pioneering Discovery.}

medicine. This field endeavors to bring together not only clinicians and researchers from diverse backgrounds, but also an expanded community and multidisciplinary audience of specialists from fields such as disease biology, bioinformatics, bioengineering, materials science, nanotechnology and neurosurgery. We again face the challenge of integrating concepts, tools and a common language and understanding among these fields.

With this in mind, The Feinstein Institute Press is pleased to announce the launch of our new journal, Bioelectronic Medicine. Published by the Feinstein Institute for Medical Research, the international, open-access, peer-reviewed journal will be wholly dedicated to disseminating works in this multidisciplinary field.

Making devices on the basis of molecular mechanisms to replace drugs or to replace biologics is an achievable goal. We are in the middle of a revolution. I hope you will join.

\section{DISCLOSURE}

The authors declare that they have no competing interests as defined by Bioelectronic Medicine, or other interests that might be perceived to influence the results and discussion reported in this paper.

\section{REFERENCES}

1. Cerami A, Warren KS. (1994) Molecular medicine: the future of biomedical science and clinical practice. Mol. Med. 1:1.

Cite this article as: Tracey KJ. (2014) The revolutionary future of bioelectronic medicine. Bioelectron. Med. 1:1. 